\title{
Determination of gas bubble fractionation rates in the deep ocean by laser Raman spectroscopy
}

\author{
S. N. White*, P. G. Brewer, E. T. Peltzer \\ Monterey Bay Aquarium Research Institute \\ Moss Landing, CA 95039-9644
}

\begin{abstract}
A new deep-sea laser Raman spectrometer (DORISS - Deep Ocean Raman In Situ Spectrometer) is used to observe the preferential dissolution of $\mathrm{CO}_{2}$ into seawater from a $50 \%-50 \% \mathrm{CO}_{2}-\mathrm{N}_{2}$ gas mixture in a set of experiments that test a proposed method of $\mathrm{CO}_{2}$ sequestration in the deep ocean. In a first set of experiments performed at $300 \mathrm{~m}$ depth, an open-bottomed $1000 \mathrm{~cm}^{3}$ cube was used to contain the gas mixture; and in a second set of experiments a $2.5 \mathrm{~cm}^{3}$ funnel was used to hold a bubble of the gas mixture in front of the sampling optic. By observing the changing ratios of the $\mathrm{CO}_{2}$ and $\mathrm{N}_{2}$ Raman bands we were able to determine the gas flux and the mass transfer coefficient at $300 \mathrm{~m}$ depth and compare them to theoretical calculations for air-sea gas exchange. Although each experiment had a different configuration, comparable results were obtained. As expected, the ratio of $\mathrm{CO}_{2}$ to $\mathrm{N}_{2}$ drops off at an exponential rate as $\mathrm{CO}_{2}$ is preferentially dissolved in seawater. In fitting the data with theoretical gas flux calculations, the boundary layer thickness was determined to be $\sim 42 \mu \mathrm{m}$ for the gas cube, and $\sim 165 \mu \mathrm{m}$ for the gas funnel reflecting different boundary layer turbulence. The mass transfer coefficients for $\mathrm{CO}_{2}$ are $k_{L}=2.82$ x $10^{-5} \mathrm{~m} / \mathrm{s}$ for the gas cube experiment, and $k_{L}=7.98 \times 10^{-6} \mathrm{~m} / \mathrm{s}$ for the gas funnel experiment.
\end{abstract}

Keywords: Instruments; Carbon Dioxide; Gas Flux; Chemical Sensor

*Corresponding author: Now at: Woods Hole Oceanographic Institution, Woods Hole, MA 02543 


\section{Introduction}

The increasing levels of $\mathrm{CO}_{2}$ in the atmosphere and its potential for global climate change have led to proposals for sequestering $\mathrm{CO}_{2}$ in the deep ocean (e.g., Brewer, 2000). For any $\mathrm{CO}_{2}$ sequestration procedure the cost and complexity of $\mathrm{CO}_{2}$ capture from the combustion stream dominates the economic equation (U.S. Department of Energy, 1999). Thus, ocean injection of a $\mathrm{N}_{2}-\mathrm{CO}_{2}$ mixture at relatively shallow depth, combined with piped transfer of the dense $\mathrm{CO}_{2}$ rich sea water formed to great ocean depth, and release of the excess $\mathrm{N}_{2}$ gas has been proposed (Saito et al., 2000). The trade off is the increased cost of pressurization of the $\mathrm{N}_{2}$ gas, and thus the use of an enriched $\mathrm{CO}_{2}$ stream is preferable. These ocean gas injection schemes rely on a rising bubble stream to provide the surface area required for rapid dissolution. We have developed techniques for direct visual observation of rising bubble (Rehder et al., 2002) and droplet (Brewer et al., 2002b) streams in the ocean.

We have carried out novel experiments to determine in situ the dissolution rate of gas mixtures injected into the deep ocean. Our purpose was to test under field conditions a proposal for ocean $\mathrm{CO}_{2}$ sequestration without prior $\mathrm{CO}_{2}$ capture (Kajishima et al., 1997; Saito et al., 2000) based upon the marked difference in solubilities of $\mathrm{CO}_{2}$ (Aya et al., 1997; Haugan and Drange, 1992) and $\mathrm{N}_{2}$ (Wiebe et al., 1933) gases in cold sea water at high pressure. The dissolution behavior of gas bubbles is of fundamental interest to ocean scientists for reasons as diverse as their role in air-sea gas exchange (Keeling, 1993), to the fate of gases vented from the deep ocean floor (Massoth et al., 1989; Merewether et al., 1985; Rehder et al., 2002). Additionally we sought to advance the use of newly developed Raman spectrometric techniques (Brewer et al., 2004; Pasteris et al., 2004) for deep-sea geochemical studies. Laser Raman spectroscopy is useful for both chemical identification and for observations of the rate of change of gas composition with time.

Raman spectrometry has seen little use as a tool by ocean scientists, but it offers the potential of rapid, non-destructive analysis of solids, liquids, and gases and recent technical developments (Brewer et al., 2004; Pasteris et al., 2004) have enabled its use in the deep sea. The complexity of the typical optical path has in the past rendered Raman most useful as a chemical identification tool rather than for quantitative analysis. However, relative concentrations of gas mixtures can readily be determined by measuring peak area ratios in the spectra, and there exists substantial opportunity for quantitative work where effective calibration protocols are possible (Sum et al., 1997; Wopenka and Pasteris, 1987). Here we take advantage of the rapidity and specificity of the Raman ratio technique and directly observe in situ the changing composition of a $\mathrm{CO}_{2}-\mathrm{N}_{2}$ gas mixture with time during two cruises in August and October of 2002 . 


\section{Methods}

\subsection{Raman Scattering}

Raman scattering is the inelastic, molecular scattering of monochromatic radiation. An incident photon exchanges energy with the target molecule and is scattered with lower or higher energy - Stokes and anti-Stokes scattering, respectively (Figure 1). The observed energy shift of the scattered radiation is equal to the change in vibrational energy of the molecule, and is not dependent on the frequency of the exciting radiation. One of the big advantages of Raman spectroscopy is that it is capable of analyzing solids, liquids, and gases. It is rapid and requires little to no sample preparation, and is (generally) nondestructive. A fuller discussion of the theory behind Raman scattering can be found in Ferraro, et al. (2003), Nakamoto (1997), and references therein.

The intensity of Raman scattering is dependent upon a number of parameters and can be written in simple form as:

$$
I_{R}=\left(I_{L} \sigma \eta\right) P \cdot C
$$

where $I_{R}$ is the measured Raman intensity, $I_{L}$ is the laser intensity, $\sigma$ is the Raman cross-section or scattering efficiency, $\eta$ includes instrument parameters such as optical transmission and collection efficiency, $P$ is the sample path length, and $C$ is the concentration (Pelletier, 1999). The Raman cross-section differs for different molecules and different phases. Additionally, Raman intensity is affected by the optical path; therefore peak heights or areas cannot necessarily be compared directly from one measurement to the next. However, peak ratio techniques, which are independent of optical path, exposure time, and other experimental factors, may be used to determine relative concentrations.

We use the ratio method of Wopenka \& Pasteris (1987) in a manner similar to Sum et al. (1997) for a two-component system to obtain an expression relating the concentration $C_{i}$ of species $A$ and $B$ to the measured Raman band areas $\left(A_{i}\right)$, Raman cross sections $\left(\sigma_{i}\right)$, and the instrumental factors $\left(\eta_{i}\right)$ by

$$
\frac{C_{A}}{C_{B}}=\frac{A_{A}}{A_{B}} \frac{\sigma_{B}}{\sigma_{A}} \frac{\eta_{B}}{\eta_{A}}=\frac{A_{A}}{A_{B}} \times \frac{F_{B}}{F_{A}}
$$

where $F_{i}$ is defined as the "Raman quantification factor." This yields an expression similar to Beer's Law, widely used in spectrophotometric procedures. In a similar manner, since the fundamental measurement of the molar absorptivities etc. is difficult, Beer's Law is usually applied by constructing a calibration curve. In this case the practical protocols for in situ calibration are still evolving, and we use here a single internal reference standard. Sum et al. (1997) have shown that $\mathrm{CH}_{4}-\mathrm{CO}_{2}$ gas mixtures measured by Raman spectroscopy have a linear calibration curve, and thus although it was not possible to introduce a number of contained known gas mixtures to the probe to provide a direct gas based calibration, we assume that the less complex $\mathrm{N}_{2}-\mathrm{CO}_{2}$ mixture also yields a linear response. 


\subsection{Instrumentation}

Direct measurements of the $\mathrm{CO}_{2}-\mathrm{N}_{2}$ gas ratio were obtained with MBARI's in situ laser Raman spectrometer system called DORISS (Deep Ocean Raman In Situ Spectrometer). This sea-going instrument is based on a laboratory model laser Raman spectrometer (LRS) from Kaiser Optical Systems and consists of a $532 \mathrm{~nm} \mathrm{Nd}: Y A G$ laser, a holographically filtered probe head, a holographic duplex grating, and a 512×2048 front illuminated CCD camera from Andor Technology. The spectral range of DORISS is 100-4400 $\Delta \mathrm{cm}^{-1}$. The duplex grating splits the spectrum into two stripes on the face of the CCD chip providing a mapping of $\sim 1 \mathrm{~cm}^{-1}$ per pixel. The resolution at the time of the deployment was $\sim 7 \mathrm{~cm}^{-1}$.

The instrument is packaged in three pressure housings connected by copper and fiber optic cables for use in the ocean to depths as great as $4000 \mathrm{~m}$ (Brewer et al., 2004). The immersion sampling optic used for this experiment has an $\mathrm{f} / 2$ lens at the end of a 10 inch-long metal tube with a sapphire window rated to $3000 \mathrm{psi}$. The working distance of the immersion optic is $4 \mathrm{~mm}$ in air, $7 \mathrm{~mm}$ in water. The spectrometer was calibrated in the lab prior to deployment. A neon source was used for wavelength calibration and a calibrated tungsten lamp was used for intensity calibration. The laser wavelength was checked by looking at the position of the $801 \Delta \mathrm{cm}^{-1}$ Raman line of cyclohexane (Tedesco and Davis, 1999). The wavelength calibration of the spectrometer can be affected by changes in temperature (DORISS experienced a temperature drop of $\sim 7^{\circ} \mathrm{C}$ during the deployment). Therefore, a diamond plate was placed in the beam path of the laser inside the probe head as a reference standard (Brewer et al., 2004; Zheng et al., 2001). The $1332 \Delta \mathrm{cm}^{-1}$ diamond Raman line is thus superimposed on all collected spectra as a calibration check.

During the time of the deployments discussed here, the instrument was still under development and some components were changed. These components include an X-Y-Z stage (referred to as a laser injector) used to couple the laser to the $62.5 \mu \mathrm{m}$ excitation fiber. The injector provided by the vendor was replaced by a more robust custom built injector which assured higher laser power output and greater stability. The laser power output was $\sim 11-13 \mathrm{~mW}$ for both deployments. Additionally, the slit alignment mechanism in the spectrometer was replaced with a motorized stage. The original slit alignment mechanism was designed to be operated manually with a thumb wheel. Thus, when the spectrometer was sealed in its pressure housing, the slit could not be aligned. Before the motorized stage was installed, no slit was used. Thus the effective slit width was $100 \mu \mathrm{m}$ (the size of the collection fiber). After the motorized stage was installed, a $50 \mu \mathrm{m}$ slit was used. Lastly, the diamond chip in the probe head was repositioned between deployments to reduce extraneous scattering off the edges of the chip.

An important characteristic of a new instrument is its detection limit. During the development of the DORISS instrument, changes in configuration have caused changes in sensitivity (and hence detection limit) from one 
experiment to another. Additionally, the detection limit is dependent upon the Raman scattering efficiency of the target which varies from one molecule to another. However, based on our August data, we can make some assumptions regarding the detection limit of the instrument. Table 1 shows the signal to noise ratio for the $\mathrm{CO}_{2}$ and $\mathrm{N}_{2}$ bands from the August data. The duplex grating used in the spectrometer, divides the spectral region into two stripes - a "high lambda" stripe $\left(\sim 0-2400 \Delta \mathrm{cm}^{-1}\right)$ and a "low lambda" stripe $\left(\sim 2200-4400 \Delta \mathrm{cm}^{-1}\right)$. The $\mathrm{N}_{2}$ band is observed on the "high lambda" stripe which has less noise. Assuming that a signal-to-noise ratio of 3 is required, DORISS is capable of detecting concentrations as low as $2.4 \mathrm{~mol} \%$ for $\mathrm{CO}_{2}$ and $2.3 \mathrm{~mol} \%$ for $\mathrm{N}_{2}$ in this configuration. It should be noted that this is most likely a conservative estimate as improvements to the system which increase sensitivity and decrease noise are currently being implemented.

\section{Table 1}

Estimates of DORISS detection limits for gaseous $\mathrm{CO}_{2}$ and $\mathrm{N}_{2}$ at 30.86 atm

\begin{tabular}{lccccc}
\hline & $\begin{array}{c}\text { Band area } \\
\text { (counts) }\end{array}$ & $\begin{array}{c}\text { RMS } \\
\text { Noise }\end{array}$ & $\begin{array}{c}\text { Signal-to- } \\
\text { Noise }\end{array}$ & $\begin{array}{c}\text { Limit of } \\
\text { Detection } \\
(\mathbf{S} / \mathbf{N}=\mathbf{3})\end{array}$ & $\begin{array}{c}\text { Limit of } \\
\text { Quantification } \\
(\mathbf{S} / \mathbf{N}=\mathbf{1 0})\end{array}$ \\
\hline $\boldsymbol{C O}_{2}$ & 2917 & 47 & $\sim 60$ & $2.4 \mathrm{~mol} \%$ & $8.1 \mathrm{~mol} \%$ \\
$\boldsymbol{N}_{2}$ & 1965 & 30 & $\sim 65$ & $2.3 \mathrm{~mol} \%$ & $7.6 \mathrm{~mol} \%$ \\
\hline
\end{tabular}

\subsection{Raman spectra analysis}

The spectral data were analyzed using GRAMS/AI data processing software (from ThermoGalactic). Nitrogen has a single Raman peak at $2332 \Delta \mathrm{cm}^{-1}$. Carbon dioxide is characterized by the Fermi diad: peaks at $\sim 1285 \Delta \mathrm{cm}^{-1}$ from the bending mode $\left(2 v_{2}\right)$ and at $\sim 1388 \Delta \mathrm{cm}^{-1}$ from the symmetric stretch mode $\left(v_{1}\right)$. The peak position (i.e., Raman shift), height and area were determined using the GRAMS/AI peak fitting routine. When identifying peaks, the same wavenumber regions were analyzed for all spectra, and baseline values were determined by the peak fitting routine for those regions. As noted above, we examined ratios of the $\mathrm{CO}_{2}$ to $\mathrm{N}_{2}$ peak areas which are independent of exposure time, optical path, and instrument configuration.

\section{Field Experiments}

DORISS was deployed in Monterey Bay using MBARI's remotely operated vehicle (ROV) Ventana (Figure 2). The ROV Ventana provides power and communications to DORISS, and is controlled by pilots and scientists aboard the support ship, the R/V Point Lobos, through a $\sim 2 \mathrm{~km}-1$ ong tether. Measurements of the gas mixture were made at depths of 100-400 m (well above the seafloor at 
that location). The ROV's external HID lights were turned off during acquisition of spectra. These lights produce strong peaks across the spectral region of the DORISS instrument.

This paper will focus on data collected at $300 \mathrm{~m}$ during two dive series. The ambient seawater temperature at that depth was $7.9^{\circ} \mathrm{C}$, and the pressure was $\sim 300$ dbar. At this temperature and pressure pure $\mathrm{CO}_{2}$ is a gas and is clearly outside of the hydrate stability field (Figure $3 \mathrm{a}$ ). However, for this experiment we used a 50-50 (mole \%) mixture of $\mathrm{CO}_{2}$ and nitrogen; for this mixture the phase boundaries are dramatically shifted due to $\mathrm{CO}_{2}-\mathrm{N}_{2}$ interactions. A liquid phase will not form under any PT conditions encountered in Monterey Bay, nor will $\mathrm{CO}_{2}$ clathrate hydrate form under the conditions of the experiment (Figure $3 \mathrm{~b}$ ); we calculated the physical properties using MultiFlash 3.2 (Infochem, Inc., London).

A 50-50 (mole \%) mixture of carbon dioxide and nitrogen was prepared by first filling an evacuated SCUBA tank to 800 psia with commercial grade $\mathrm{CO}_{2}$ at ambient temperature $\left(21.9^{\circ} \mathrm{C}\right)$ and then filling with UHP nitrogen gas to 1600 psia. This second step was done in two parts by allowing the cylinder to cool to ambient temperature overnight between fillings. We estimate that the composition is within $\pm 5 \%$ of the target mixture based upon uncertainties in the pressure and temperature at time of filling. The SCUBA tank was allowed to sit to achieve complete mixing of the gases for 40 hours before use. The same gas mixture was used for both the August and October deployments.

\subsection{August 2002 experiments}

A preliminary set of measurements was obtained in August 2002. During this experiment, the immersion optic was inserted into a hole in the side of an openbottomed $1000 \mathrm{~cm}^{3}$ cube; thus the optic tip was in a pocket of gas and no seawater was in the beam path (Figure 4). The gas cube was filled with a $50 \%$ $50 \% \mathrm{CO}_{2}-\mathrm{N}_{2}$ gas mixture from a port at the top of the box; thus, very little mixing with seawater occurred during filling. A second valve allowed the box to vent gas upwards while filling with seawater through the open bottom. With this configuration we were easily able to collect quality spectra of a 50\%-50\% mixture of $\mathrm{CO}_{2}$ and $\mathrm{N}_{2}$ gas and $100 \% \mathrm{~N}_{2}$ gas. Two sets of measurements where collected at $300 \mathrm{~m}$ depth - a series of $10 \times 10 \mathrm{sec}$ accumulations spanning 23 minutes, and a series of $5 \times 5$ sec accumulations spanning 16 minutes. The box was purged and refilled with gas before each experiment.

The gas cube experiment provided a baseline to understand the relative intensities of the Raman signals from $\mathrm{CO}_{2}$ and $\mathrm{N}_{2}$. We were also able to observe the preferential dissolution of $\mathrm{CO}_{2}$ into seawater. However, due to the low ratio of the seawater-exposed area to the gas volume $\left(\sim 0.1 \mathrm{~cm}^{-1}\right)$ we were not able to observe the complete diffusion of $\mathrm{CO}_{2}$ from the gas cube during the time of our experiment ( 30 minutes). 


\subsection{October 2002 experiments}

In October of 2002 we performed another series of experiments to observe the preferential dissolution of $\mathrm{CO}_{2}$ from a $50 \%-50 \% \mathrm{CO}_{2}-\mathrm{N}_{2}$ gas mixture. Based upon the results from our August cruise we were able to scale the experiment appropriately, such that complete $\mathrm{CO}_{2}$ dissolution could be observed in $~ 30$ minutes. The probe head was positioned in a downward-looking orientation and a clear conical funnel was placed on the tip of the immersion optic to hold a buoyant gas bubble in the DORISS beam path (Figure 5). The total volume of the funnel was $2.5 \mathrm{~cm}^{3}$, and the ratio of the exposed area to the gas volume was increased 20-fold from the earlier gas cube experiment.

Two experiments were run with the funnel configuration, both at a depth of $300 \mathrm{~m}$, with spectra being collected every 5 minutes over a 30 minute period. During the first run, each spectrum was an average of 10 accumulations of 10 second exposures. Thus, each spectrum was an average over a time span of 100 seconds. During the second run, each spectrum was an average of fifteen 15 second exposures (time span of 225 seconds). The funnel was thoroughly flushed with the gas mixture prior to each experiment.

\section{Results}

\subsection{August 2002 data}

The data from the August dives provide information on the relative Raman scattering efficiencies of nitrogen and carbon dioxide. Initial spectra from both experiments are shown in Figure 6. The two $\mathrm{CO}_{2}$ peaks $\left(\sim 1285\right.$ and $\left.\sim 1388 \Delta \mathrm{cm}^{-1}\right)$ are separated by the diamond reference peak $\left(1332 \Delta \mathrm{cm}^{-1}\right)$ in the left half of the spectrum; the $\mathrm{N}_{2}$ peak $\left(2332 \Delta \mathrm{cm}^{-1}\right)$ is on the right half of the spectrum. The dropout at $1942 \Delta \mathrm{cm}^{-1}$ is due to a flaw on the CCD chip. We compared the area ratios of both $\mathrm{CO}_{2}$ bands to the $\mathrm{N}_{2}$ band to examine any differences in the Raman efficiencies. Immediately after the cube was filled, the ratio of the $\mathrm{CO}_{2}$ bend band $\left(\sim 1285 \Delta \mathrm{cm}^{-1}\right)$ to $\mathrm{N}_{2}$ was $\sim 1.1$; the ratio of the $\mathrm{CO}_{2}$ stretch band $\left(\sim 1388 \Delta \mathrm{cm}^{-1}\right)$ to $\mathrm{N}_{2}$ was $\sim 1.9$. These ratios were the same for both sets of measurements - 10 x $10 \mathrm{sec}$ exposures and 5 x $5 \mathrm{sec}$ exposures. The peak area ratios observed over time (Figure 7) show the decrease in $\mathrm{CO}_{2}$ relative to $\mathrm{N}_{2}$ in the gas mixture. The 5 x 5 sec accumulations show more scatter in the data than the 10 x $10 \mathrm{sec}$ accumulations as expected due to higher noise levels in shorter exposures.

\subsection{October 2002 data}

The data from the October dives provide information on the rate at which $\mathrm{CO}_{2}$ is preferentially dissolved into seawater. Two sets of measurements were made with the small funnel configuration (Figure 5) - a series of 10 x $10 \mathrm{sec}$ accumulations and a series of 15 x 15 sec accumulations each spanning $~ 30$ minutes. It should be noted that in the raw data the diamond peak area is 
approximately the same in the October data as it is in the August data. However, the peak areas of the gas components are 2.5 times as strong in the August data as they are in the October data. This is due to the changes in the instrument between cruises and differences in the optical path for the two experiments (i.e., the large gas cube used in August versus the small gas funnel used in October). Despite the fact that the absolute peak area values are different, the peak area ratios are not affected and can be compared.

The October data show starting ratios of $\sim 1.5$ for the $\mathrm{CO}_{2}$ stretch band to $\mathrm{N}_{2}$, and $\sim 0.8$ for the $\mathrm{CO}_{2}$ bend band to $\mathrm{N}_{2}$. These numbers are slightly lower than those observed from the August dives ( $\sim 1.9$ and $\sim 1.1$, respectively). This is likely due to the fact that a) the gas is bubbled up into the funnel through seawater allowing some gas dissolution, and b) the scaling of the experiment leads to faster dissolution of $\mathrm{CO}_{2}$ as compared to the gas cube experiment. Thus, some $\mathrm{CO}_{2}$ dissolution has already occurred before (or while) the initial spectra are being obtained. Calculations and comparisons with the August data suggest that the starting ratio for the October experiments is actually $\sim 44 \%-56 \%$ $\mathrm{CO}_{2}-\mathrm{N}_{2}$.

During the October experiments, the complete dissolution of $\mathrm{CO}_{2}$ can be observed within 30 minutes. Spectra were collected every five minutes during this time and show the decreasing $\mathrm{CO}_{2}$ Raman peaks (Figure 8). The $\mathrm{CO}_{2}$ peaks were much smaller in the October measurements than they were in the August measurements (Figure 6) with respect to the diamond peak. By plotting the ratios over time we can fit an exponential curve to the data (Figure 9, Table 2). The exponential drop off of the data is due to the fact that since $\mathrm{CO}_{2}$ is preferentially dissolved, the mole fraction of $\mathrm{CO}_{2}$ in the gas mixture decreases over time which leads to a slowing of the dissolution rate.

Table 2

Curve Fits for October 2002 data

\begin{tabular}{|c|c|c|}
\hline Area Ratios & Least Squares Fit & $\mathbf{r}^{2}$ \\
\hline \multicolumn{3}{|c|}{ Experiment $1-10 \times 10 \mathrm{sec}$} \\
\hline $\mathrm{CO}_{2}$ stretch $/ \mathrm{N}_{2}$ & $1.60 e^{-0.0587 x}$ & 0.989 \\
\hline $\mathrm{CO}_{2}$ bend $/ \mathrm{N}_{2}$ & $0.865 \mathrm{e}^{-0.0583 x}$ & 0.970 \\
\hline \multicolumn{3}{|c|}{ Experiment $2-15 \times 15 \mathrm{sec}$} \\
\hline $\mathrm{CO}_{2}$ stretch $/ \mathrm{N}_{2}$ & $1.44 \mathrm{e}^{-0.0536 \mathrm{x}}$ & 0.947 \\
\hline $\mathrm{CO}_{2}$ bend $/ \mathrm{N}_{2}$ & $0.724 \mathrm{e}^{-0.0532 \mathrm{x}}$ & 0.904 \\
\hline
\end{tabular}




\section{Discussion}

\subsection{Air-sea gas exchange}

The mechanism of gas exchange across an air-water interface has been studied for years in order to better understand ocean interaction with the overlying atmosphere which has implications for global climate. Researchers typically use two-layer models where thin boundary layers are present in both the gas phase and the liquid phase (e.g., Liss and Slater, 1974), or single-layer stagnant boundary layer models where a gradient exists only in the water layer (e.g., Broecker and Peng, 1974). These models assume that both the air and water layers are well mixed while gradients exist only in thin films at the interface.

Our gas dissolution experiments provide a small-scale look at gas transfer across a gas-liquid interface at high pressure, and absent turbulent wind forcing of either the gas or water components; only local ocean water velocities perturb the interface. We assume that both the gas volume and the seawater below it are well mixed, however we do not have knowledge of the diffusive boundary layer thickness. Our initially 50\%-50\% $\mathrm{CO}_{2}-\mathrm{N}_{2}$ gas mixture changes composition with time and decreases in total volume as gas is transferred to the seawater below. We will use typical values for the stagnant boundary layer model to calculate expected fluxes and concentrations and compare them to the data collected with the DORISS system.

The gas exchange rate of $\mathrm{CO}_{2}$ presents a special case due to the complex chemistry involved (Zeebe and Wolf-Gladrow, 2001). Typically it is the much slower rate of atmosphere-ocean $\mathrm{CO}_{2}$ gas exchange that engages the attention of ocean chemists. Bolin (1960) first drew attention to this, and the phenomenon is due to the buffer capacity of seawater and the relatively long time scales to achieve chemical equilibrium in the oceanic mixed layer within the aqueous $\mathrm{CO}_{2}$ system. The net result is a gas exchange rate for $\mathrm{CO}_{2} \cong 10 \mathrm{x}$ slower than for typical atmospheric gases, including nitrogen. However, the approximately $10 \mathrm{x}$ greater solubility of $\mathrm{CO}_{2}$ in seawater (Aya et al., 1997; Haugan and Drange, 1992; Rehder et al., 2004) until the hydrate phase boundary is reached, results in far faster dissolution rates.

\subsection{Theoretical calculations}

Since we may neglect the complexities of the ocean-atmosphere boundary layer, we may use a simple rendition of the gas exchange equation. From Henry's Law the amount of gas dissolved in a volume of solvent $\left(C_{l}\right)$ is proportional to the partial pressure of the gas $\left(P_{g}\right)$ in the gas volume $(\mathrm{atm})$ in equilibrium with the solution, and the ratio can be described by a solubility constant, $K(\mathrm{~mol} / \mathrm{L} / \mathrm{atm})$.

$$
C_{l}=K \cdot P_{g}
$$

Using the stagnant film model (Broecker and Peng, 1974; Broecker and Peng, 1982), the flux of gas across the interface can be calculated by 


$$
F=D \cdot \frac{C_{t o p}-C_{b o t t o m}}{z} \cdot \frac{1}{1000}
$$

where $F$ is the gas flux $\left(\mathrm{mol} / \mathrm{cm}^{2} / \mathrm{s}\right), D$ is the coefficient of molecular diffusion $\left(\mathrm{cm}^{2} / \mathrm{s}\right), C_{t o p}$ and $C_{\text {bottom }}$ are the concentrations at the top and the bottom of the boundary layer $(\mathrm{mol} / \mathrm{L})$, and $z$ is the thickness of the boundary layer $(\mathrm{cm})$. The bottom of the boundary layer is in equilibrium with the seawater below $\left(C_{s w}\right)$ and the top of the boundary layer is in equilibrium with the gas layer above (Equation 3). Therefore, Equation 4 can be rewritten as

$$
F=D \cdot \frac{K \cdot P_{g}-C_{s w}}{z}
$$

Values for the equilibrium concentration in seawater, diffusion coefficient, and solubility of $\mathrm{CO}_{2}$ and $\mathrm{N}_{2}$ are given in Table $3 \mathrm{a}$ for the surface ocean at 1 atm and in Table $3 \mathrm{~b}$ for a depth of $300 \mathrm{~m}$ and 30.86 atm pressure. Literature values for the boundary layer thickness obtained from laboratory experiments vary from $\sim 10$ to $\sim 300 \mu \mathrm{m}$, while radiocarbon calculations suggest an average ocean boundary layer thickness of $\sim 40 \mu \mathrm{m}$ (Broecker and Peng, 1974).

At the beginning of the experiment, the partial pressures of $\mathrm{CO}_{2}$ and $\mathrm{N}_{2}$ in the gas volume are the same (15.43 atm). The values for the equilibrium concentration in seawater, diffusion coefficient, and solubility of $\mathrm{CO}_{2}$ and $\mathrm{N}_{2}$ at $300 \mathrm{~m}$ depth are given in Table $3 \mathrm{~b}$. Equation 3 shows that for both $\mathrm{CO}_{2}$ and $\mathrm{N}_{2}$, the dissolved gas concentration in equilibrium with the gas phase is higher than the gas concentration in seawater. Therefore, both gases should dissolve into seawater over time. Using Equation 5 and assuming a boundary layer thickness of $40 \mu \mathrm{m}$, we find that the flux of $\mathrm{CO}_{2}$ into seawater $\left(1.27 \times 10^{-6} \mathrm{~mol} / \mathrm{cm}^{2} / \mathrm{s}\right)$ is much higher than that of $\mathrm{N}_{2}\left(4.45 \times 10^{-8} \mathrm{~mol} / \mathrm{cm}^{2} / \mathrm{s}\right)$ due to its higher solubility. Therefore, the concentration of $\mathrm{N}_{2}$ in the gas phase should increase over time as $\mathrm{CO}_{2}$ is preferentially dissolved.

\section{Table 3a}

Gas properties for $\mathrm{CO}_{2}$ and $\mathrm{N}_{2}$ in the surface ocean (1 atm)

\begin{tabular}{lcc}
\hline & $\mathbf{C O}_{2}$ & $\mathbf{N}_{2}$ \\
\hline Gas concentration in seawater, $C_{s w}(\mathrm{~mol} / \mathrm{L}) @ 0^{\circ} \mathrm{C}^{\mathrm{a}}$ & $2.00 \times 10^{-5}$ & $6.20 \times 10^{-4}$ \\
Diffusion coefficient, $D\left(\mathrm{~cm}^{2} / \mathrm{s}\right) @ 8^{\circ} \mathrm{C}^{\mathrm{b}}$ & $1.17 \times 10^{-5}$ & $1.21 \times 10^{-5}$ \\
Solubility, $K(\mathrm{~mol} / \mathrm{L} / \mathrm{atm}) @ 8^{\circ} \mathrm{C}^{\mathrm{c}}$ & $4.72 \times 10^{-2}$ & $6.46 \times 10^{-4}$ \\
\hline
\end{tabular}

\footnotetext{
From Broecker \& Peng (1982).

b Broecker \& Peng (1974), Jähne et al. (1987)

c From Weiss (1974), Weiss (1970).
} 


\section{Table 3b}

Gas properties for $\mathrm{CO}_{2}$ and $\mathrm{N}_{2}$ at $300 \mathrm{~m}$ depth $(30.86 \mathrm{~atm})$

\begin{tabular}{|c|c|c|}
\hline & $\mathrm{CO}_{2}$ & $\mathbf{N}_{2}$ \\
\hline Gas concentration in seawater, $C_{s w}(\mathrm{~mol} / \mathrm{kg}) @ 8^{\circ} \mathrm{C}^{\mathrm{a}, \mathrm{b}}$ & $4.90 \times 10^{-5}$ & $5.36 \times 10^{-4}$ \\
\hline Diffusion coefficient, $D\left(\mathrm{~cm}^{2} / \mathrm{s}\right) @ 8^{\circ} \mathrm{C}^{\mathrm{c}}$ & $1.17 \times 10^{-5}$ & $1.21 \times 10^{-5}$ \\
\hline Solubility, $K(\mathrm{~mol} / \mathrm{L} / \mathrm{atm}) @ 8^{\circ} \mathrm{C}^{\mathrm{d}}$ & $2.80 \times 10^{-2}$ & $9.89 \times 10^{-4}$ \\
\hline $\begin{array}{ll}\text { a } & \text { From CO2sys version 01.05 (Lewis, BNL). } \\
\text { b } & \text { From Weiss (1970). } \\
\text { c } & \text { Broecker \& Peng (1974), Jähne et al. (1987); Note that diffus } \\
& \text { pressure. }\end{array}$ & at is not signific & affected by \\
\hline
\end{tabular}

\subsection{Comparison with Raman measurements}

From Equation 2, we see that the area ratio of the $\mathrm{CO}_{2}$ and $\mathrm{N}_{2}$ Raman bands is proportional to the ratio of their concentrations. We know the initial concentration of the gases in the gas mixture, which provides us with a calibration point. We can then determine the concentration ratio of the gas mixture over time from the ratio of the Raman peak areas. The mole fractions are determined from the concentration ratios over time and can be compared to theoretical calculations based on the gas flux equation (Equation 5) above.

We first looked at the $10 \times 10$ sec data from the August 2002 experiment using the $1000 \mathrm{~cm}^{3}$ gas cube. The cube shape maintains a constant exposed surface area $\left(100 \mathrm{~cm}^{2}\right)$ as the gas volume decreases. The signal-to-noise ratio of the instrument appears to have been higher by a factor of 5 during this deployment compared to the October deployment. Additionally, the slow rate of dissolution is a good match for the long exposure times (i.e., $10 \mathrm{x} 10 \mathrm{sec}$ accumulations, $100 \mathrm{sec}$ total exposure time). The observed data is shown in Table 4. The peak areas of the $\mathrm{CO}_{2}$ bands (stretching band: $\sim 1388 \Delta \mathrm{cm}^{-1}$; bending band: $\sim 1285 \Delta \mathrm{cm}^{-1}$ ) decrease over time corresponding to a decrease in mole fraction and concentration. The peak area of the $\mathrm{N}_{2}$ peak $\left(\sim 2332 \Delta \mathrm{cm}^{-1}\right)$ increases over time, corresponding to an increase in mole fraction and concentration. Concentration ratios are calculated from the ratios of both $\mathrm{CO}_{2}$ bands to nitrogen. As expected, the concentration ratios determined from each $\mathrm{CO}_{2}$ band are quite similar. The mean value of the concentration ratio is used to determine the mole fractions of $\mathrm{CO}_{2}$ and $\mathrm{N}_{2}$. The density of the gas mixture is calculated using MultiFlash 3.2 from the mole fractions.

Table 5 shows calculated values for moles, mole fraction, partial pressure and gas flux over time. This data is based on the initial conditions (shown in the first row of Table 4) and flux calculations discussed in the previous section. A boundary layer thickness $(z)$ of $\sim 42 \mu \mathrm{m}$ is needed to approximate the observed 
data. As expected the gas flux of $\mathrm{CO}_{2}$ is much higher than that of $\mathrm{N}_{2}$ (by a factor of almost 30). As the $\mathrm{CO}_{2}$ is preferentially dissolved into seawater its mole fraction and flux decrease over time. This slowing of the flux causes the observed exponential drop-off of the data (Figure 9). Based on the calculations, the change in volume of the gas over $1200 \mathrm{sec}$ is $89.88 \mathrm{~cm}^{3}$. By looking at video frame grabs of the experiment, we observed that the gas volume has decreased by approximately $1 \mathrm{~cm}$ in height which is $\sim 100 \mathrm{~cm}^{3}$ in volume.

The same observational to theoretical comparison can be made for the October data from the $2.5 \mathrm{~cm}^{3}$ gas funnel. Due to the shape of the funnel, the surface area exposed to seawater decreases over time as the gas volume decreases. Table 6 shows the observed data from the $10 \times 10$ second experiments. As noted in section 4.3, the starting gas mixture appears to be $44 \%-56 \% \mathrm{CO}_{2}$ $\mathrm{N}_{2}$. The calculated values of moles, mole fraction, partial pressure, and gas flux are shown in Table 7. Unlike the calculations for the August data, a boundary layer thickness of $\sim 165 \mu \mathrm{m}$ is necessary to approximate the data from the October experiment, possibly due to reduced boundary layer turbulence within the small gas funnel. The rate of change in gas composition in the October experiment is also higher (by as much as an order of magnitude) than those in the August experiment. This is due to the higher seawater-exposed area to gas volume ratio as noted in section 3.2.

A comparison of the observed and theoretical data from the August and October experiments is shown in Figure 10. Due to the volume/exposed surface area scaling of the experiment, the proportion of $\mathrm{CO}_{2}$ loss occurs more rapidly in the October experiment. In both cases, the theoretical calculations match quite well to the observed data. The August data shows a slight curvature that is not matched by the theoretical line. This may be due to the fact that as the gas volume in the cube decreases an enriched liquid layer is confined in the lower portion of the cube which slows the dissolution rate over time.

Page 12 of 24 
Table 4

Observation of $\mathrm{CO}_{2}$ and $\mathrm{N}_{2}$ dissolution from the $1000 \mathrm{~cm}^{3}$ gas cube (August 2002, 10x10 sec data)

\begin{tabular}{|c|c|c|c|c|c|c|c|c|c|}
\hline \multirow{2}{*}{$\begin{array}{l}\text { Elapsed } \\
\text { Time } \\
\text { (minutes) }\end{array}$} & \multicolumn{3}{|c|}{$\begin{array}{c}\text { Observed Peak Area } \\
\text { (counts) }\end{array}$} & \multicolumn{2}{|c|}{$\begin{array}{c}\text { Observed Concentration } \\
\text { Ratios }\end{array}$} & \multirow{2}{*}{$\begin{array}{c}\text { Mean } \\
\text { Conc. } \\
\text { Ratio } \\
\mathrm{CO}_{2} / \mathrm{N}_{2}\end{array}$} & \multicolumn{2}{|c|}{$\begin{array}{l}\text { Mean Observed } \\
\text { Mole Fraction }\end{array}$} & \multirow{2}{*}{$\begin{array}{c}\text { Mean } \\
\text { Density } \\
(\mathrm{g} / \mathrm{cm} 3)\end{array}$} \\
\hline & $\mathrm{CO}_{2}$-bend & $\mathrm{CO}_{2}$-stretch & $\mathrm{N}_{2}$ & $\begin{array}{c}\mathrm{CO}_{2} \text {-bend } \\
/ \mathrm{N}_{2}\end{array}$ & $\begin{array}{c}\mathrm{CO}_{2} \text {-stretch } \\
/ \mathrm{N}_{2}\end{array}$ & & $\mathrm{CO}_{2}$ & $\mathrm{~N}_{2}$ & \\
\hline 2.835 & 6570 & 11510 & 5970 & 1.0000 & 1.0000 & 1.0000 & 0.5000 & 0.5000 & 0.05247 \\
\hline 7.835 & 6244 & 10619 & 6217 & 0.9127 & 0.8859 & 0.8993 & 0.4735 & 0.5265 & 0.05156 \\
\hline 17.835 & 6355 & 10961 & 6888 & 0.8383 & 0.8254 & 0.8319 & 0.4541 & 0.5459 & 0.05091 \\
\hline 22.835 & 6152 & 10294 & 6714 & 0.8326 & 0.7953 & 0.8140 & 0.4487 & 0.5513 & 0.05074 \\
\hline
\end{tabular}

\section{Table 5}

\section{Theoretical calculation for the $1000 \mathrm{~cm}^{3}$ gas cube}

\begin{tabular}{|c|c|c|c|c|c|c|c|c|c|}
\hline \multirow{2}{*}{$\begin{array}{l}\text { Elapsed } \\
\text { Time } \\
\text { (minutes) }\end{array}$} & \multicolumn{3}{|c|}{$\begin{array}{c}\text { Calculated Moles } \\
\text { in Gas Cube } \\
\text { (moles) }\end{array}$} & \multicolumn{2}{|c|}{$\begin{array}{c}\text { Calculated Mole } \\
\text { Fractions }\end{array}$} & \multicolumn{2}{|c|}{$\begin{array}{c}\text { Calculated Partial } \\
\text { Pressure } \\
(\mathrm{atm})\end{array}$} & \multicolumn{2}{|c|}{$\begin{array}{l}\text { Calculated Gas Flux } \\
\qquad\left(\mathrm{mol} / \mathrm{cm}^{2} / \mathrm{sec}\right)\end{array}$} \\
\hline & $\mathrm{CO}_{2}$ & $\mathrm{~N}_{2}$ & Total & $\mathrm{CO}_{2}$ & $\mathrm{~N}_{2}$ & $\mathrm{CO}_{2}$ & $\mathrm{~N}_{2}$ & $\mathrm{CO}_{2}$ & $\mathrm{~N}_{2}$ \\
\hline 2.835 & 0.7252 & 0.7252 & 1.4505 & 0.5000 & 0.5000 & 15.43 & 15.43 & $1.22 \mathrm{E}-06$ & $4.29 E-08$ \\
\hline 7.835 & 0.6890 & 0.7239 & 1.4130 & 0.4876 & 0.5124 & 15.05 & 15.81 & $1.19 \mathrm{E}-06$ & $4.40 \mathrm{E}-08$ \\
\hline 12.835 & 0.6537 & 0.7226 & 1.3763 & 0.4750 & 0.5250 & 14.66 & 16.20 & $1.16 \mathrm{E}-06$ & $4.52 \mathrm{E}-08$ \\
\hline 17.835 & 0.6193 & 0.7212 & 1.3406 & 0.4620 & 0.5380 & 14.26 & 16.60 & $1.13 \mathrm{E}-06$ & $4.63 \mathrm{E}-08$ \\
\hline 22.835 & 0.5859 & 0.7198 & 1.3058 & 0.4487 & 0.5513 & 13.85 & 17.01 & $1.09 \mathrm{E}-06$ & $4.75 \mathrm{E}-08$ \\
\hline
\end{tabular}




\section{Table 6}

Observation of $\mathrm{CO}_{2}$ and $\mathrm{N}_{2}$ dissolution from the $2.5 \mathrm{~cm}^{3}$ gas funnel (October 2002 , 10x10 sec data)

\begin{tabular}{|c|c|c|c|c|c|c|c|c|c|}
\hline \multirow{2}{*}{$\begin{array}{l}\text { Elapsed } \\
\text { Time } \\
\text { (minutes) }\end{array}$} & \multicolumn{3}{|c|}{$\begin{array}{c}\text { Observed Peak Area } \\
\text { (counts) }\end{array}$} & \multicolumn{2}{|c|}{$\begin{array}{c}\text { Observed Concentration } \\
\text { Ratios }\end{array}$} & \multirow{2}{*}{$\begin{array}{c}\text { Mean } \\
\text { Conc. } \\
\text { Ratio }\end{array}$} & \multicolumn{2}{|c|}{$\begin{array}{l}\text { Mean Observed } \\
\text { Mole Fraction }\end{array}$} & \multirow{2}{*}{$\begin{array}{c}\text { Mean } \\
\text { Density } \\
(\mathrm{g} / \mathrm{cm} 3)\end{array}$} \\
\hline & $\mathrm{CO}_{2}$-bend & $\mathrm{CO}_{2}$-stretch & $\mathrm{N}_{2}$ & $\begin{array}{c}\mathrm{CO}_{2} \text {-bend } \\
/ \mathrm{N}_{2} \\
\end{array}$ & $\begin{array}{c}\mathrm{CO}_{2} \text {-stretch } \\
/ \mathrm{N}_{2} \\
\end{array}$ & & $\mathrm{CO}_{2}$ & $\mathrm{~N}_{2}$ & \\
\hline 0.835 & 1470 & 2917 & 1966 & 0.6795 & 1.0000 & 0.8398 & 0.4565 & 0.5435 & 0.05099 \\
\hline 5.835 & 1382 & 2330 & 1965 & 0.6392 & 0.6150 & 0.6271 & 0.3854 & 0.6146 & 0.04870 \\
\hline 10.835 & 1033 & 2007 & 2092 & 0.4488 & 0.4978 & 0.4733 & 0.3213 & 0.6787 & 0.04672 \\
\hline 15.835 & 925 & 1498 & 2279 & 0.3687 & 0.3411 & 0.3549 & 0.2619 & 0.7381 & 0.04497 \\
\hline 20.835 & 602 & 1258 & 2394 & 0.2286 & 0.2726 & 0.2506 & 0.2004 & 0.7996 & 0.04321 \\
\hline 25.835 & 578 & 998 & 2561 & 0.2052 & 0.2022 & 0.2037 & 0.1692 & 0.8308 & 0.04234 \\
\hline 31.665 & 321 & 602 & 2547 & 0.1146 & 0.1225 & 0.1186 & 0.1060 & 0.8940 & 0.04062 \\
\hline
\end{tabular}




\section{Table 7}

Theoretical calculation for the $2.5 \mathrm{~cm}^{3}$ gas funnel

\begin{tabular}{|c|c|c|c|c|c|c|c|c|c|}
\hline \multirow{2}{*}{$\begin{array}{l}\text { Elapsed } \\
\text { Time } \\
\text { (minutes) }\end{array}$} & \multicolumn{3}{|c|}{$\begin{array}{c}\text { Calculated Moles } \\
\text { in Gas Cube } \\
\text { (moles) }\end{array}$} & \multicolumn{2}{|c|}{$\begin{array}{l}\text { Calculated Mole } \\
\text { Fractions }\end{array}$} & \multicolumn{2}{|c|}{$\begin{array}{c}\text { Calculated } \\
\text { Partial Pressure } \\
(\mathrm{atm})\end{array}$} & \multicolumn{2}{|c|}{$\begin{array}{c}\text { Calculated Gas Flux } \\
\left(\mathrm{mol} / \mathrm{cm}^{2} / \mathrm{sec}\right)\end{array}$} \\
\hline & $\mathrm{CO}_{2}$ & $\mathrm{~N}_{2}$ & Total & $\mathrm{CO}_{2}$ & $\mathrm{~N}_{2}$ & $\mathrm{CO}_{2}$ & $\mathrm{~N}_{2}$ & $\mathrm{CO}_{2}$ & $\mathrm{~N}_{2}$ \\
\hline 0.835 & 0.001648 & 0.001962 & 0.003610 & 0.4565 & 0.5435 & 14.09 & 16.77 & $3.15 \mathrm{E}-07$ & $1.32 \mathrm{E}-08$ \\
\hline 5.835 & 0.001242 & 0.001943 & 0.003185 & 0.3899 & 0.6101 & 12.03 & 18.83 & $2.69 \mathrm{E}-07$ & $1.49 \mathrm{E}-08$ \\
\hline 10.835 & 0.000918 & 0.001923 & 0.002841 & 0.3231 & 0.6769 & 9.97 & 20.89 & $2.23 \mathrm{E}-07$ & $1.66 \mathrm{E}-08$ \\
\hline 15.835 & 0.000666 & 0.001902 & 0.002568 & 0.2594 & 0.7406 & 8.01 & 22.85 & $1.79 \mathrm{E}-07$ & $1.82 \mathrm{E}-08$ \\
\hline 20.835 & 0.000475 & 0.001880 & 0.002355 & 0.2017 & 0.7983 & 6.23 & 24.63 & $1.39 \mathrm{E}-07$ & $1.97 \mathrm{E}-08$ \\
\hline 25.835 & 0.000333 & 0.001857 & 0.002190 & 0.1522 & 0.8478 & 4.70 & 26.16 & $1.05 \mathrm{E}-07$ & $2.09 \mathrm{E}-08$ \\
\hline 31.665 & 0.000217 & 0.001830 & 0.002046 & 0.1060 & 0.8940 & 3.27 & 27.59 & $7.31 \mathrm{E}-08$ & $2.21 \mathrm{E}-08$ \\
\hline
\end{tabular}




\section{Conclusions}

Saito et al. (2000) have proposed a method for $\mathrm{CO}_{2}$ sequestration that employs a gas-lift pump (GLAD - Gas Lift Advanced Dissolution) system and would be effective for low-purity $\mathrm{CO}_{2}$. From laboratory experiments at atmospheric pressure, they have determined the mass transfer coefficients $\left(k_{L}\right)$ for pure $\mathrm{CO}_{2}$ and a mix of $95 \% \mathrm{CO}_{2}$ and $5 \%$ air (Saito et al., 1999). The average mass transfer coefficient for $\mathrm{CO}_{2}$ is $2.0 \times 10^{-4} \mathrm{~m} / \mathrm{s}$, and that of the low purity $\mathrm{CO}_{2}$ is slightly less. Our work performed at a depth of $300 \mathrm{~m}$ (the depth proposed for gas injection in the GLAD system) using a 50\%-50\% $\mathrm{CO}_{2}-\mathrm{N}_{2}$ mixture shows a lower $\mathrm{CO}_{2}$ mass transfer coefficient: $k_{L}=7.98 \times 10^{-6} \mathrm{~m} / \mathrm{s}$ for the gas funnel experiment. Saito (1999) showed that the mass transfer coefficient is lower for lower purity $\mathrm{CO}_{2}$, and this is supported by our lower numbers for a $50 \% \mathrm{CO}_{2}$ gas mixture.

Laser Raman spectroscopy is a useful and valuable tool for performing in situ analysis in the deep ocean. Changing processes can be observed in realtime, and both qualitative and quantitative data can be obtained. The novel in situ spectroscopic techniques we have devised will enhance many $\mathrm{CO}_{2}$ and gas hydrate studies (e.g., Brewer et al., 2002a; Brewer et al., 2002b; Rehder et al., 2002; Rehder et al., 2004), and can be extended to a very wide range of ocean science, including hydrothermal vent studies.

\section{Acknowledgements}

We acknowledge the help and support of the pilots of the ROV Ventana, and the captain and crew of the RV Point Lobos for their skilled assistance with the field work. We acknowledge the valuable assistance of J. Pasteris, B. Wopenka, and J. Freeman in the development of the DORISS system; the engineering support of Mark Brown, Danelle Cline and George Malby; and technical assistance from Peter Walz and Randy Prickett. Funding was provided by a grant to

MBARI from the David and Lucile Packard Foundation, and by the U.S. Dept. of Energy Ocean Carbon Sequestration Program (Grants No. DE-FC26-00NT40929 and DE-FC03-01ER6305). This paper has benefited from the reviews of Dr. Gregor Rehder and Prof. Gordon Taylor. 


\section{References}

Aya, I., Yamane, K. and Nariai, H., 1997. Solubility of $\mathrm{CO}_{2}$ and density of $\mathrm{CO}_{2}$ hydrate at $30 \mathrm{MPa}$. Energy, 22(2/3): 263-271.

Bolin, B., 1960. On the exchange of carbon dioxide between the atmosphere and the sea. Tellus, 12: 274-281.

Brewer, P.G., 2000. Contemplating action: Storing carbon dioxide in the ocean. Oceanogr., 13(2): 84-92.

Brewer, P.G., Malby, G.E., Pasteris, J.D., White, S.N., Peltzer, E.T., Wopenka, B., Freeman, J. and Brown, M.O., 2004. Development of a laser Raman spectrometer for deep-ocean science. Deep-Sea Res., 51:

DOI:10.1016/j.dsr.2003.11.005.

Brewer, P.G., Paull, C., Peltzer, E.T., Ussler, W., Rehder, G. and Friederich, G., $2002 \mathrm{a}$. Measurements of the fate of gas hydrates during transit through the ocean water column. Geophys. Res. Lett., 29(22): 10.1029/2002GL014727.

Brewer, P.G., Peltzer, E.T., Friederich, G. and Rehder, G., 2002b. Experimental determination of the fate of rising $\mathrm{CO} 2$ droplets in seawater. Environ. Sci. Technol., 36: 5441-5446.

Broecker, W.S. and Peng, T.-H., 1974. Gas exchange rates between air and sea. Tellus, 26: 21-35.

Broecker, W.S. and Peng, T.-H., 1982. Tracers in the Sea. Lamont-Doherty Geological Observatory, Palisades, NY, 690 pp.

Ferraro, J.R., Nakamoto, K. and Brown, C.W., 2003. Introductory Raman Spectroscopy. Academic Press, San Diego, CA.

Haugan, P.M. and Drange, H., 1992. Sequestration of $\mathrm{CO}_{2}$ in the deep ocean by shallow injection. Nature, 357(6376): 318-320.

Jähne, B., Heinz, G. and Dietrich, W., 1987. Measurement of the diffusion coefficients of sparingly soluble gases in water. J. Geophys. Res., 92(C10): $10,767-10,776$.

Kajishima, T., Saito, T., Nagaosa, R. and Kosugi, S., 1997. GLAD: A gas-lift method for $\mathrm{CO}_{2}$ disposal into the ocean. Energy, 22(2/3): 257-262.

Keeling, R.F., 1993. On the role of large bubbles in air-sea gas exchange and supersaturation in the ocean. J. Mar. Res., 51(2): 237-271.

Liss, P.S. and Slater, P.G., 1974. Flux of gases across the air-sea interface. Nature, 247: 181-184.

Massoth, G.J., Butterfield, D., Lupton, J., McDuff, R.E., Lilley, M.D. and Jonasson, I.R., 1989. Submarine venting of phase-separated hydrothermal fluids at Axial Volcano, Juan de Fuca Ridge. Nature, 340: 702-705.

Merewether, R., Olsson, M.S. and Lonsdate, P., 1985. Acoustically detected hydrocarbon plumes rising from 2-km depths in Guaymas Basin, Gulf of California. J. Geophys. Res., 90(4): 3075-3085. 
Nakamoto, K., 1997. Infrared and Raman Spectra of Inorganic and Coordination Compounds: Part A. John Wiley \& Sons, Inc., New York, NY, 387 pp.

Pasteris, J.D., Wopenka, B., Freeman, J.J., Brewer, P.G., White, S.N., Peltzer, E.T. and Malby, G.E., 2004. Raman spectroscopy in the deep ocean: successes and challenges. Appl. Spec., 58(7): 195A-208A.

Pelletier, M.J. (Editor), 1999. Analytical Applications of Raman Spectroscopy. Blackwell Science Ltd., Oxford, 478 pp.

Rehder, G., Brewer, P.G., Peltzer, E.T. and Friederich, G., 2002. Enhanced lifetime of methane bubble streams within the deep ocean. Geophys. Res. Lett., 29(15): 10.1029/2001GL013966.

Rehder, G., Kirby, S.H., Durham, W., Stern, L., Peltzer, E.T., Pinkston, J. and Brewer, P.G., 2004. Dissolution rates of pure methane hydrate and carbondioxide hydrate in undersaturated seawater at $1000 \mathrm{~m}$ depth. Geochim. Cosmochim. Acta, 68: 285-292.

Saito, T., Kajishima, T. and Nagaosa, R., 2000. $\mathrm{CO}_{2}$ sequestration at sea by gaslift system of shallow injection and deep releasing. Environ. Sci. Technol., 34(19): 4140-4145.

Saito, T., Kajishima, T., Tsuchiya, K. and Kosugi, S., 1999. Mass transfer and structure of bubbly flows in a system of $\mathrm{CO}_{2}$ disposal into the ocean by gaslift column. Chem. Eng. Sci., 54: 4945-4951.

Sum, A.K., Burruss, R.C. and Sloan, E.D., 1997. Measurement of clathrate hydrates via Raman spectroscopy. J. Phys. Chem. B, 101: 7371-7377.

Tedesco, J.M. and Davis, K.L., 1999. Calibration of dispersive Raman process analyzers. Proc. SPIE, 3537: 200-212.

U.S. Department of Energy, 1999. Carbon Sequestration Research and Development, Oak Ridge National Lab.

Weiss, R.F., 1970. The solubility of nitrogen, oxygen and argon in water and seawater. Deep Sea Res., 17: 721-735.

Weiss, R.F., 1974. Carbon dioxide in water and seawater: the solubility of a non-ideal gas. Mar. Chem., 2: 203-215.

Wiebe, R., Gady, V.L. and Heins, C., 1933. The solubility of nitrogen in water at 50, 75, and $100 \mathrm{deg}$ from 25 to 1000 atmospheres. J. Am. Chem. Soc., 55: 947-953.

Wopenka, B. and Pasteris, J.D., 1987. Raman intensities and detection limits of geochemically relevant gas mixtures for a laser Raman microprobe. Anal. Chem., 59: 2165-2170.

Zeebe, R. and Wolf-Gladrow, D., 2001. $\mathrm{CO}_{2}$ in Seawater: Equilibrium, Kinetics, Isotopes. Elsevier, $346 \mathrm{pp}$.

Zheng, X., Fu, W., Albin, S., Wise, K.L., Javey, A. and Cooper, J.B., 2001. Self-referencing Raman probes for quantitative analysis. Appl. Spectrosc., 55(4): 382-388. 


\section{Figures}

Figure 1. Raman scattering is the inelastic scattering of monochromatic radiation. An incident photon exchanges energy with the target molecule and is scattered with lower energy (Stokes scattering) than the incident energy.

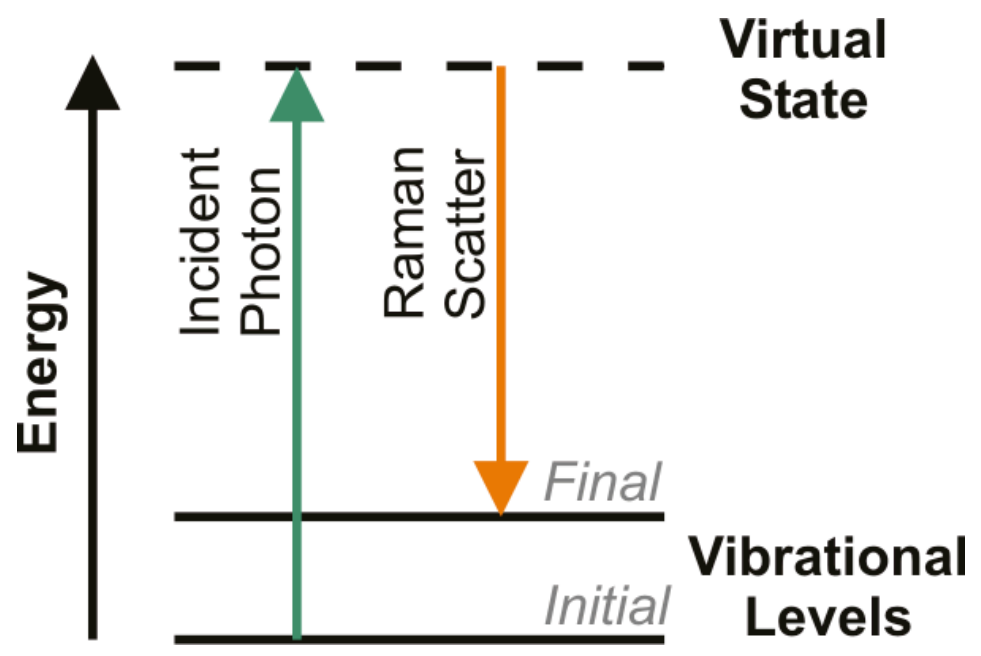

Figure 2. The DORISS instrument on the ROV Ventana. The spectrometer housing and electronics housings are mounted in a drawer in the ROV toolsled (shown by arrow). The probe head is carried in front (left in the picture below) for deployment by the ROV manipulator.

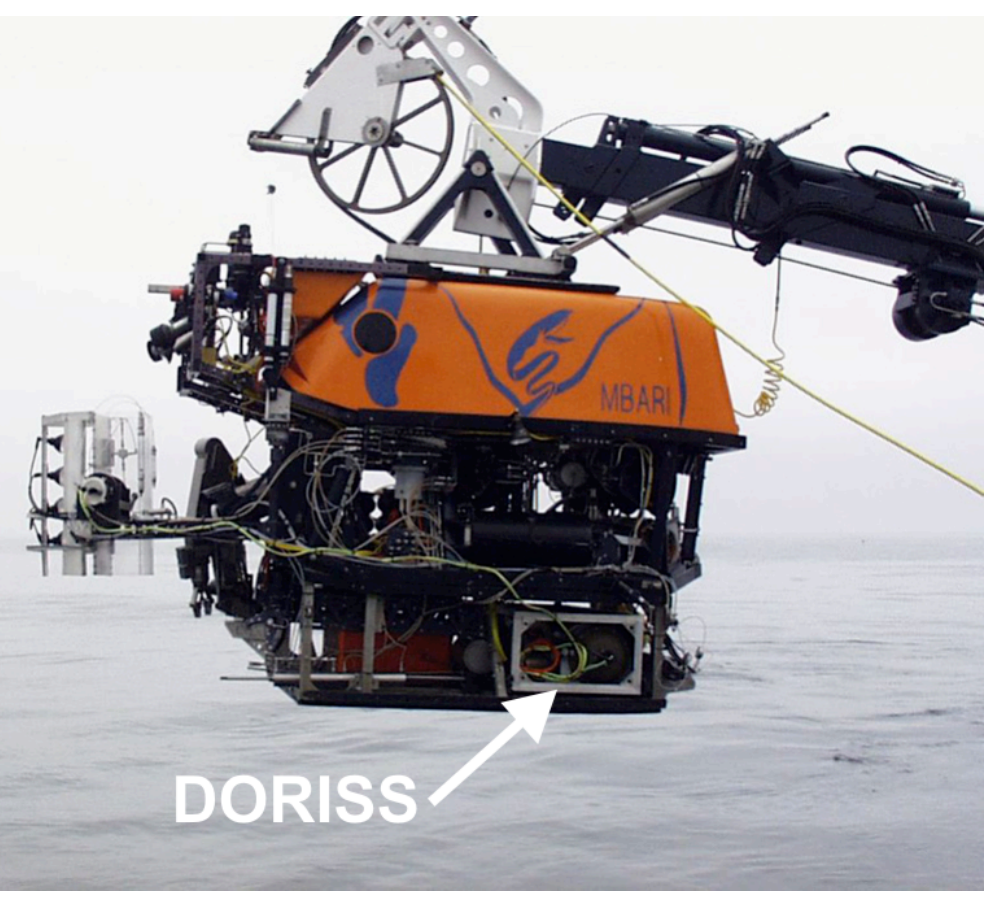


Figure 3. Phase diagram for pure $\mathrm{CO}_{2}$ in seawater (A) and 50\%-50\% $\mathrm{CO}_{2}-\mathrm{N}_{2}$ mixture in seawater (B) calculated using MultiFlash 3.2 (Infochem, Inc., London). The grey regions indicate the hydrate stability zones, the dash-dotted line indicates the liquid gas boundary. The red line is a temperature profile from Monterey Bay, and the $\mathrm{X}$ indicates the experimental conditions of our deployments.
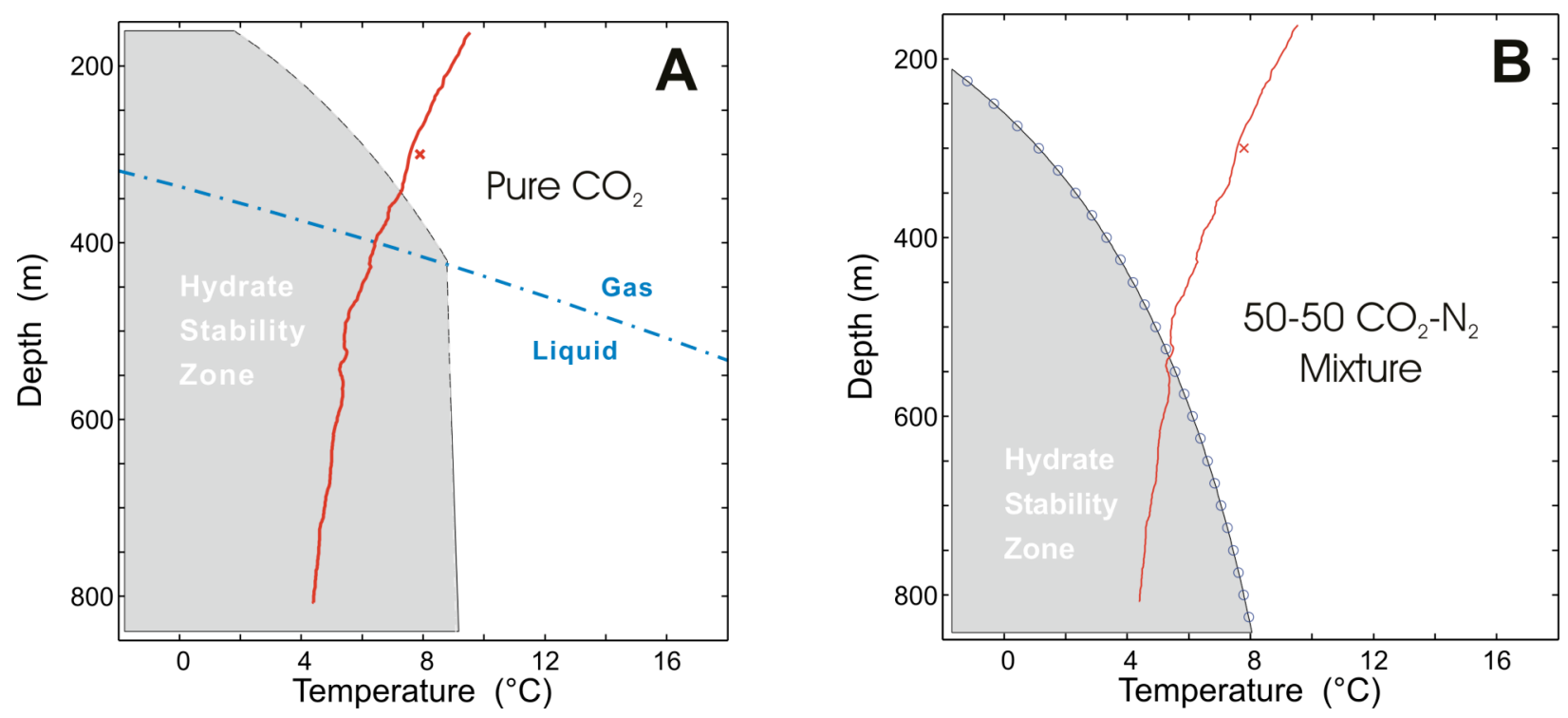

Figure 4. A video frame grab showing the DORISS probe tip penetrating the open-bottomed gas cube $(10 \times 10 \times 10 \mathrm{~cm})$. The ports at the top of the cube are used to fill and vent the cube. (From Brewer et al., 2004)

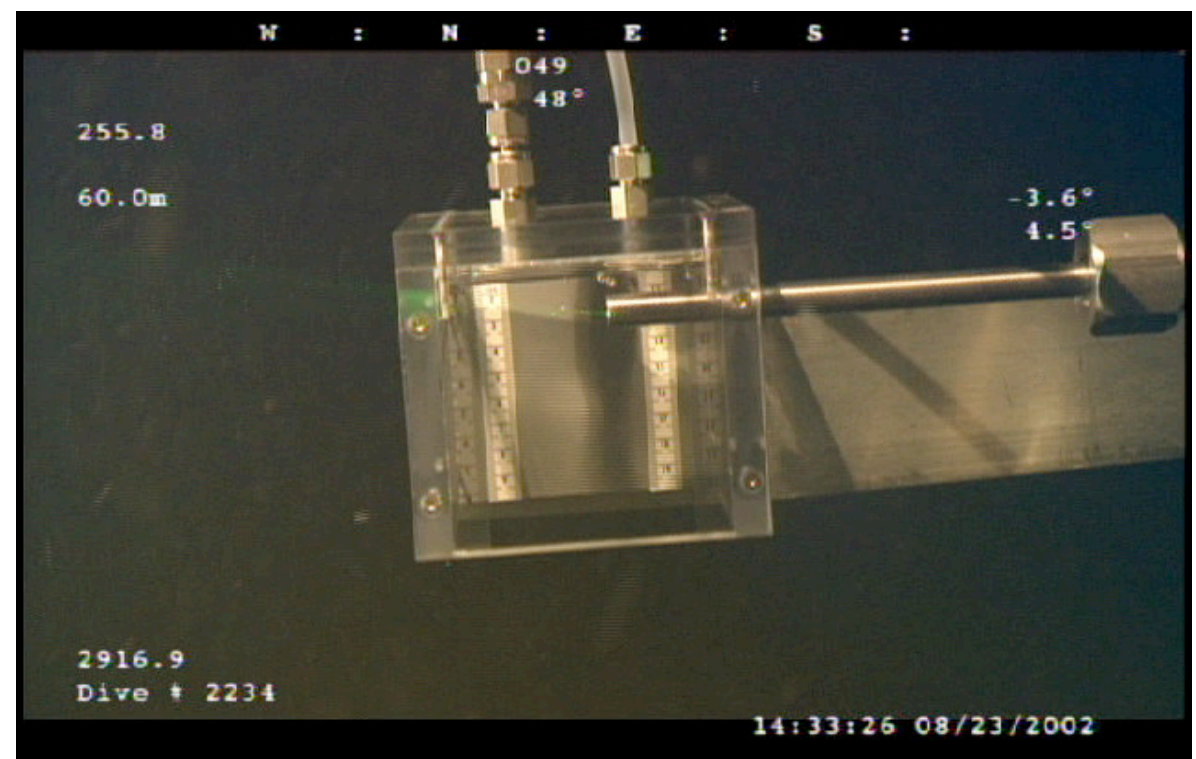


Figure 5. a) A frame grab showing the DORISS probe tip with gas funnel and gas dispensing tube. b) A cross-section of the experimental set up.
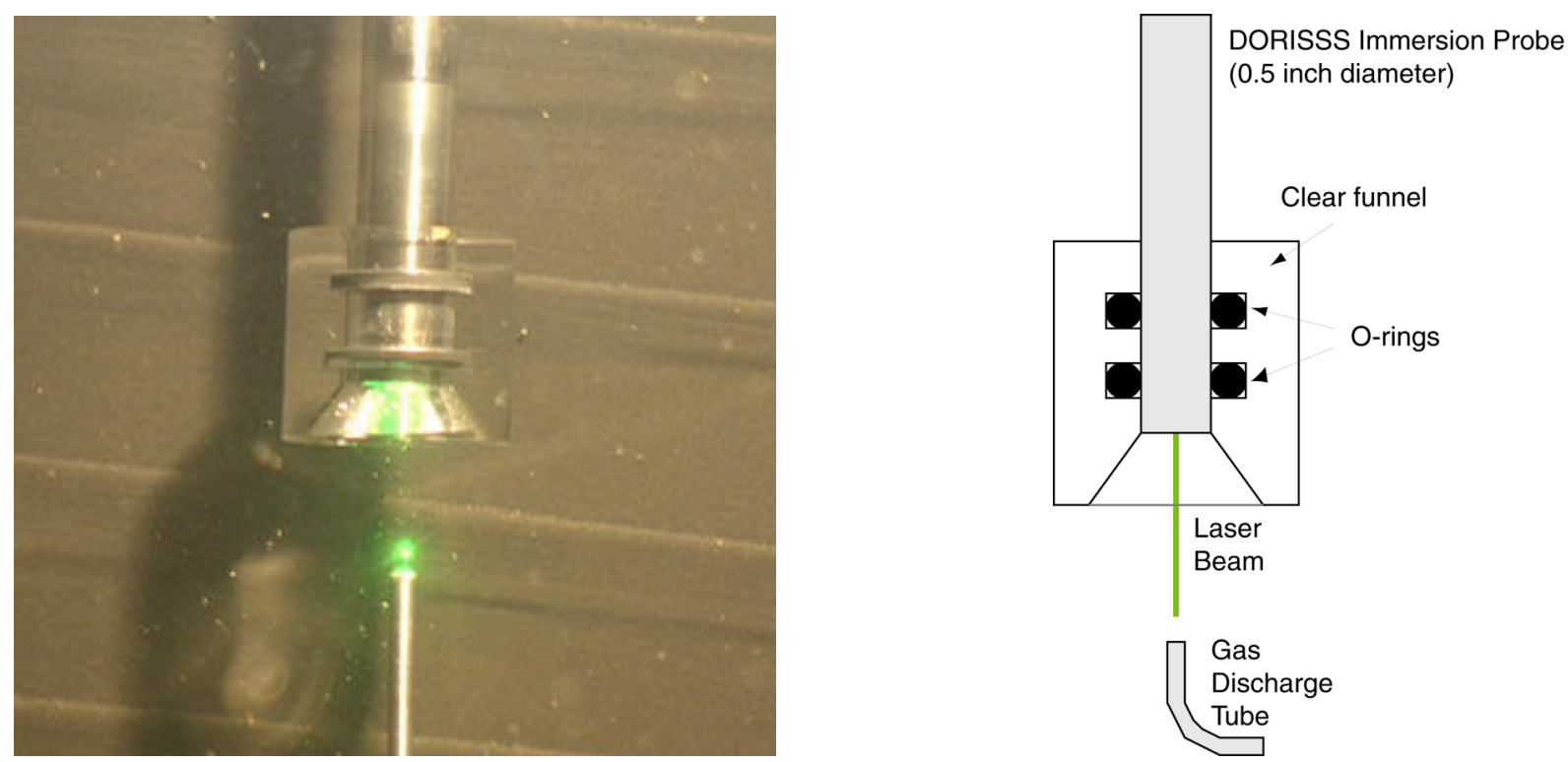

Figure 6. Raman spectra of 50\%-50\% $\mathrm{CO}_{2}-\mathrm{N}_{2}$ gas mixture in gas cube during August 2002 dives. The diamond reference peak is at $1332 \Delta \mathrm{sm}^{-1}$. The two $\mathrm{CO}_{2}$ peaks are at $1285 \Delta \mathrm{cm}^{-1}$ (bending mode) and $1388 \Delta \mathrm{cm}^{-1}$ (stretching mode). The $\mathrm{N}_{2}$ peak is at $2332 \Delta \mathrm{cm}^{-1}$. The drop out at $\sim 1900 \Delta \mathrm{cm}^{-1}$ is due to a flaw on the CCD chip.

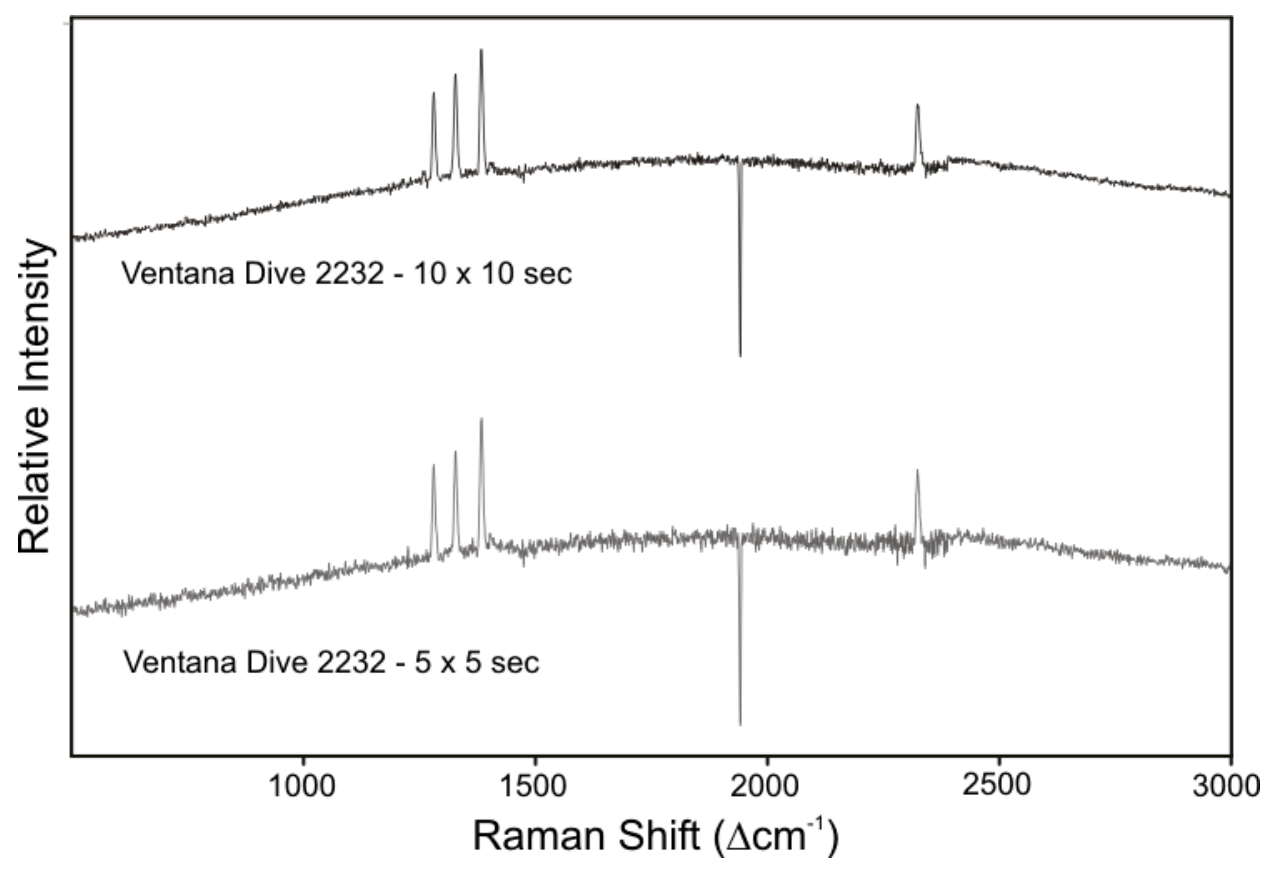


Figure 7. Peak area ratios over time from the August 2002 gas cube experiment. Data points are plotted at the midpoint of the accumulation time.

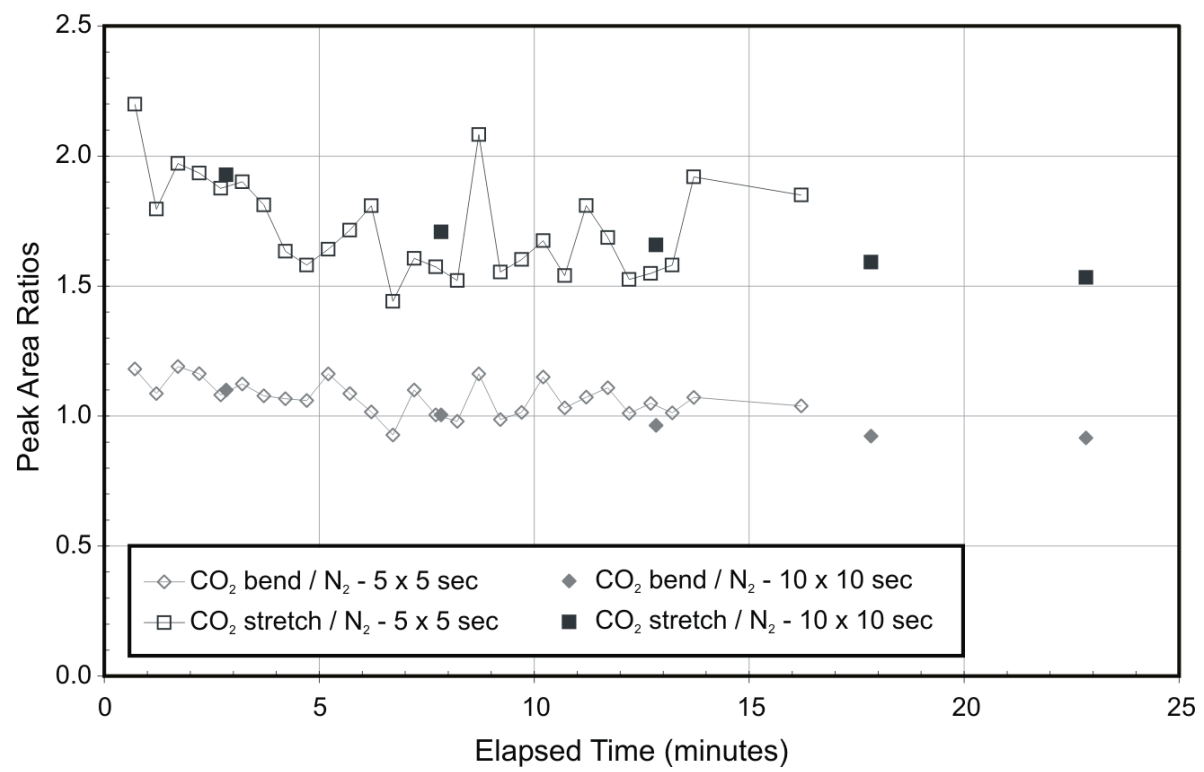

Figure 8. Raman spectra of $\mathrm{CO}_{2}$ over time. Each spectrum is an average of fifteen 15 -second exposures ( 3.75 minute average). The diamond reference peak is at $1332 \Delta \mathrm{cm}^{-1}$. The two $\mathrm{CO}_{2}$ peaks are at $1285 \Delta \mathrm{cm}^{-1}$ and $1388 \Delta \mathrm{cm}^{-1}$ and decrease over time as $\mathrm{CO}_{2}$ is dissolved into seawater. The $\mathrm{N}_{2}$ peak is at 2332 $\Delta \mathrm{cm}^{-1}$ and is not shown in this segment of the spectra.

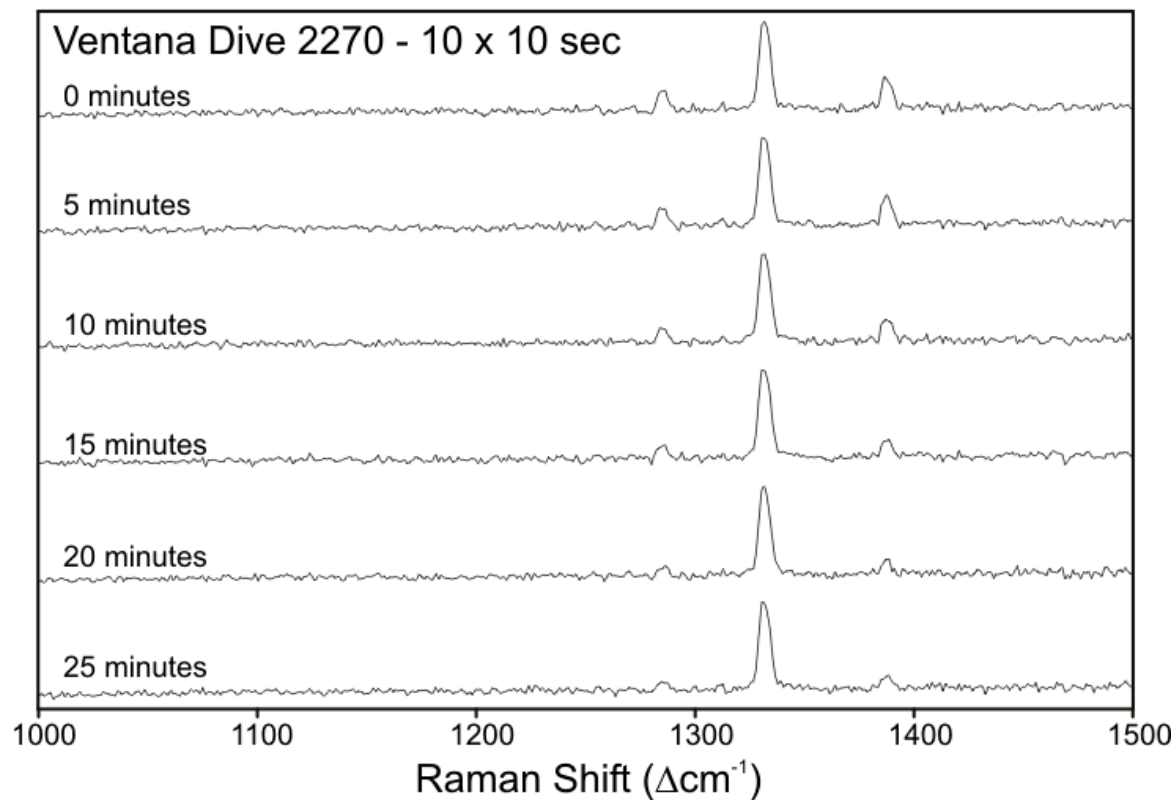

Page 22 of 24 
Figure 9. Peak area ratios over time for the October 2002 gas funnel experiments. Spectra from experiment 1 are averages of ten 10-second exposures (1.67 minute averages). Spectra from experiment 2 are averages of fifteen 15 -second exposures (3.75 minute averages). The decrease in the ratios of the peak areas of the $\mathrm{CO}_{2}$ bands to $\mathrm{N}_{2}$ band can be fit by an exponential curve. Data points are plotted at the midpoint of the accumulation time.

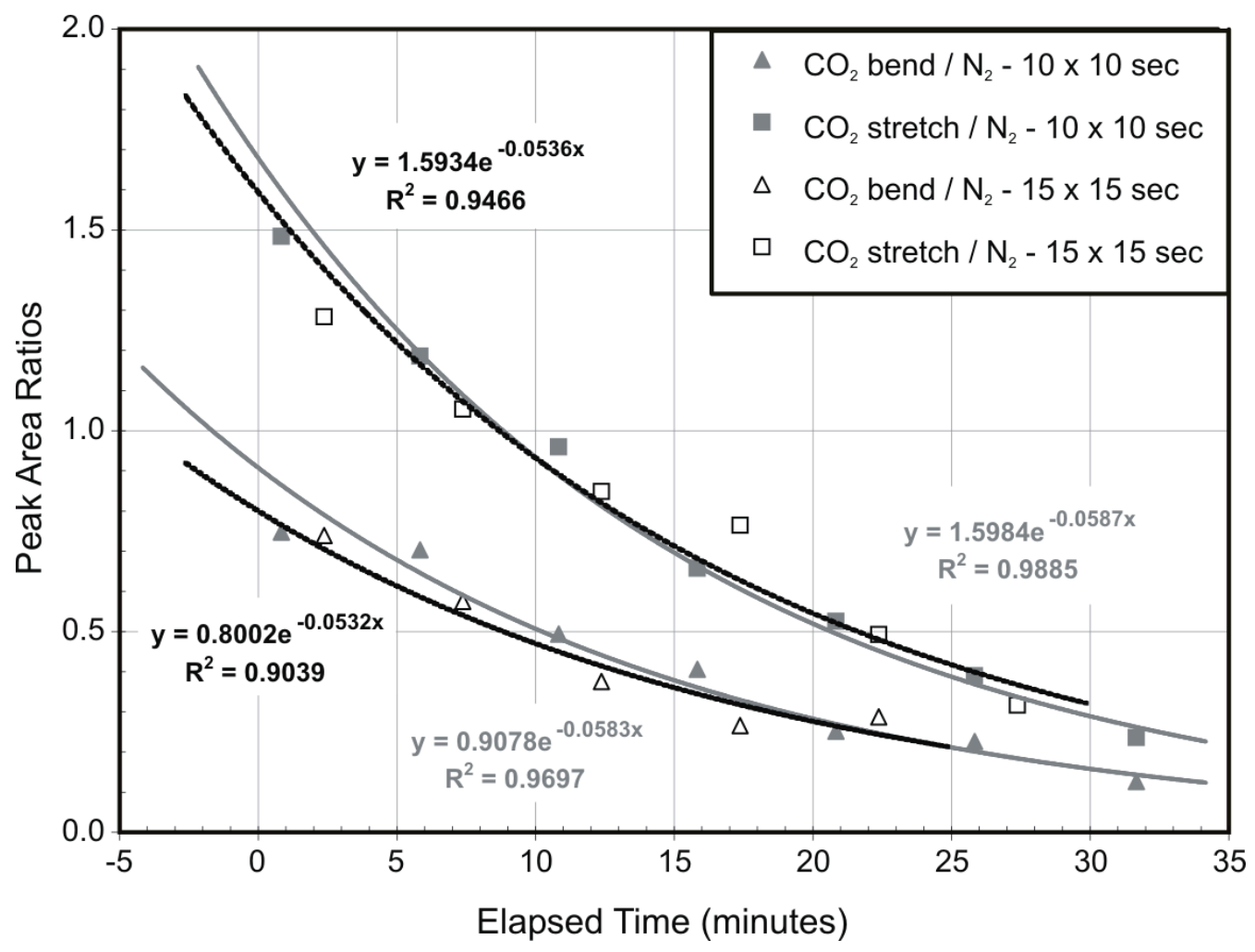

Page 23 of 24 
Figure 10. Observed and calculated $\mathrm{CO}_{2}$ mole fraction from August and October deployments. The symbols indicate the observed values, the lines indicate the mole fraction calculated using the gas flux equation.

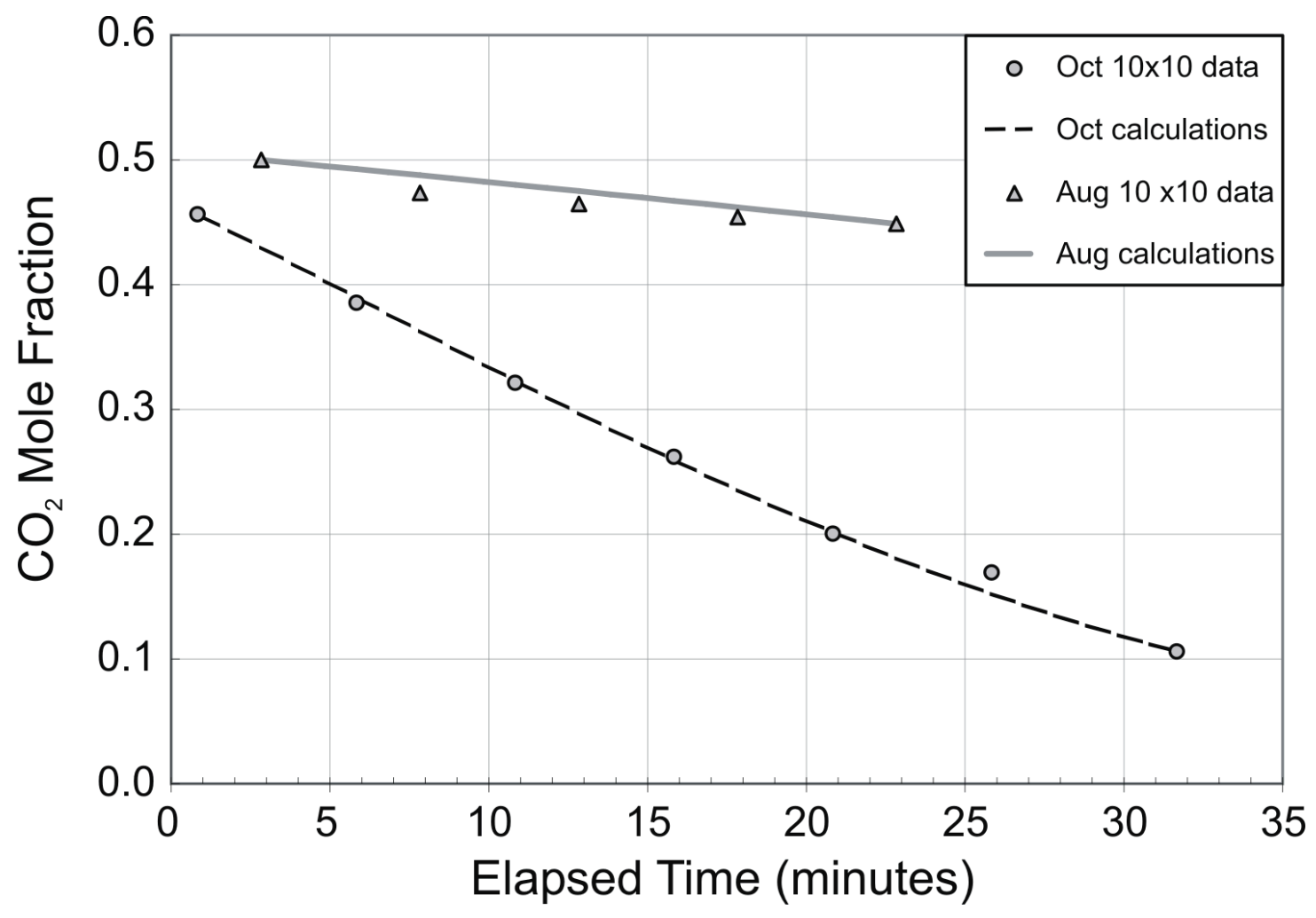

